\title{
WHO REGIONAL COMMITTEE FOR EUROPE
}

At the meeting of the above Committee held in London recently (19-23 September 1978), Dr Stanley Browne was given an opportunity of addressing the delegations from Member States on behalf of The International Leprosy Association. The following summary of his speech appears in the Report of the Meeting:

Dr Browne (International Leprosy Association) recalled that indigenous leprosy remained a sizeable and still virtually uncontrolled problem in a number of European countries, notably countries of Southern Europe and the USSR; that was quite apart from the problem of imported leprosy. Naturally, however, leprosy in Europe was only of very small relative importance when compared with the situation in countries of the Third World. He would accordingly, together with the Director-General of the World Health Organization, plead for greater recognition by the countries of Europe of their medical, social and moral obligations for the health problems of the developing countries. He urged closer links between existing expertise so that resources could be deployed for the benefit of leprosy sufferers, particularly in the realms of microbiology, immunology and therapeutics. As Chairman of the WHO Expert Committee on Leprosy, he had warned governments of the gravity of the problems of drug resistance and persister organisms, and of the urgent need to give more serious attention to the problem of leprosy. He drew attention to the International Leprosy Congress to be held in Mexico City in November of the present year. 